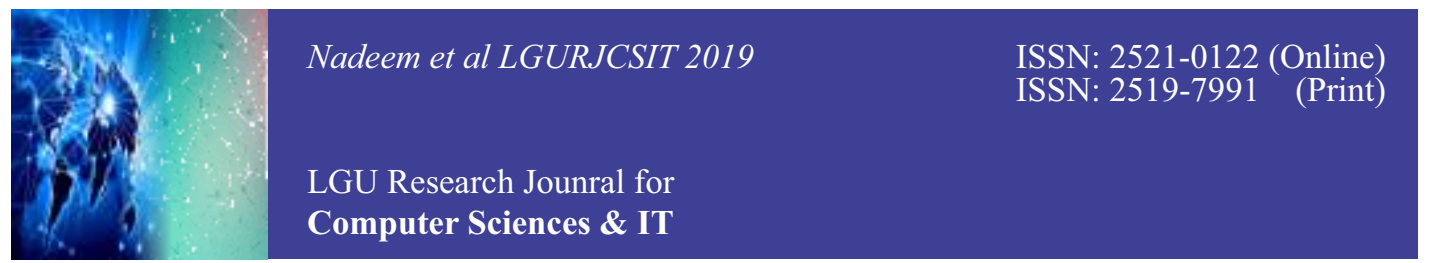

Vol. 3 Issue 2, April - June 2019

\title{
Diagnosis Health Effects of Pollution Produced by Coal Power Plants Using Mamdani Fuzzy Inference System
}

Waqas Nadeem ${ }^{1,} M$ Sajid Farooq ${ }^{2}$

${ }^{1}$ University of Management \& Technology

${ }^{2} \mathrm{NCBA} \& \mathrm{E}$ Lahore.

\section{Abstract:}

Coal Power Plants emit harmful products which pose potentially large risk to human health and the environment. Coal-fired power plant are source of nitrogen oxide, airborne fly ash and Sulphur. In substantially less attentions has been paid to detect the effect of these toxic elements present in coal pollution on the human health. In this Article, Fuzzy System (FS) is proposed to detect the Health effects of pollution produced by coal power plants. The proposed DHEPCPP-FS Smart System can categorize the different Health effects of pollution produced by coal power plants. The Proposed DHEPCPP-MFIS Expert System has six input variables at layer. The input variables are Carbon monoxide (CO). Black carbon, Nitrogen dioxide $\left(\mathrm{NO}_{2}\right)$, Sulfur dioxide $\left(\mathrm{SO}_{2}\right)$, Heavy metals and Black smoke which produce output condition of health like Lungs problem, Heart problem or Cancer. This paper also present an scrutiny of the results achieved by using Proposed DHEPCPP-MFIS Expert System ascertain effects of pollution on health produced by coal power plants processes with the medical expert opinion and researches conducted in the past.

Keywords: Mamdani fuzzy inference system, carbon monoxide (CO), pollution, nitrogen dioxide $\left(\mathrm{NO}_{2}\right)$, Sulfur dioxide $\left(\mathrm{SO}_{2}\right)$

\section{Introduction}

The use of coal in power plants is the reason of so many deaths in the population. People with lungs condition, children, adults, and women are the main victim of air pollution. The coal power plants are one of the main sources of air pollution. Gases which are produced by coal power plants is harmful to people health and can cause many harmful effects on people health. Air pollution with the aid of pollution can affect the respiratory system as well as cause lungs problem, heart problem or can cause cancer.

Outdoor and indoor air quality are crucial to human health. The common $70 \mathrm{~kg}$ grown up inhales about $20 \mathrm{~m} 3$ of air in step per day [1]. So, any boom inside the air pollution can also motive a terrific damage to the health as outdoor air additionally serves as a chief source of particulate and gaseous pollutants for indoor air [2].
Coal should be washed in mined first before using in coal power plants and then transported from mines to the power plants and the remaining particles should be properly disposed of. People living near the coal power plants are the main victims. In many countries, electricity is produced with the help of coal. The half combustion of coal produces harmful gases which can affect the human health and can cause many diseases. Diesel emissions in coal power plants is also the large contributor to air pollution black.

Smoke and heavy metals are produced by diesel emission. The waste of coal power plants mixed with the water and can cause infection and harmful disease to the people living near power plants. Landfills that leak fly ash waste can contaminate floor and surface water with Arsenic, Cadmium, Barium, Thallium, Selenium, and Lead [3].

In the region of coal fired power plants, publicity to emissions relies upon elements such 
as weather (temperature, precipitation, windroute and velocity) and topographical capabilities of the neighborhood region. Emissions also can be transported lengthy distances, even globally, causing health effects to the one residing some distance from power plants. In many develop countries coal power plants is far distance from the residing areas.

There are different tests data are conducted for Health effects of pollution produced by coal power plants. After the tests it is known that if the person inhales polluted air consist of Carbon monoxide, Black carbon, Nitrogen dioxide, Sulfur dioxide, Heavy metals and Black smoke it must be cause Lungs problem, Heart problems or Cancer.

There are unique data analysis techniques are used some of them are machine learning, statistical, data abstraction [4-5].

\section{Literature Review}

In 2011, the World Health Organization compiled air quality statistics from 1,100 cities in 91 countries and determined that residents residing in many urban areas are exposed to persistently elevated levels of fine particle pollution. The report states, "In both developed and developing countries, the biggest contributors to urban outdoor air pollution include motor transport, small-scale manufacturers and other industries, burning of biomass and coal for cooking and heating, as well as coal-fired power plants" [6].

In present, artificial insight is utilizing to analyze distinctive kinds of therapeutic issues. Insightful frameworks are creating to determine the medicals issues [7]. Fluffy surmising framework is the extremely amazing master framework to look into the issues and offer their answers. FIS is extremely helpful in which potential outcomes of vulnerability may happen.

A vital part of the wellbeing effect of coal-consuming force plants is the measure of the in danger populaces. While populaces living in closeness to coal control plants are generally little, the consequences for wellbeing could be seen in a lot bigger populaces living moderately a long way from the wellspring of introduction. For instance, the assessments for utilization of the Best Available Control Technology (BACT) on 2 old coal fired control plants in Massachusetts demonstrated that while the most extreme yearly normal advantage happens inside $25-40 \mathrm{~km}$ (contingent upon power plant) from power plant (where under $10 \%$ of the populace lives), a lion's share of advantages could be acquired for the bigger populace living similarly as $100 \mathrm{~km}$ from the source [8].

Ghopal Upadhyaya \& Nilesh Dashore presented a fuzzy system for monitoring of air pollution [9]. Archit Aggarwal et al. introduce a fuzzy interface system for determining the Air Quality Index [10]. Lancaster introduce a medical device in his paper on the basis of Fuzzy logic control (FLC) [11]. Aparna \& Shailja presents Application of Neuro-Fuzzy in prediction of Air Pollution in Urban areas the application is designed to show the forecast of $\mathrm{O} 3$ depend on $\mathrm{NO} 2$ and $\mathrm{SO} 2$ measurements [12]. Manish \& Sedamkar design a medical diagnosis expert system using fuzzy logic Inference System [13]. Lokeshappa \& Kamath introduce feasibility analysis of Air Quality Indices (AQI) using fussy logic is mainly a health-related index [14]. Dagar, et al. introduced a FIS system to diagnosis the different diseases on the basis of basic symptoms [15].

\section{Proposed Single Layer MFIS based DHEPCPP Expert System}

Proposed Diagnosis Health effects of pollution produced by coal power plants (DHEPCPP) Fuzzy System (MFIS) based Smart System (DHEPCPP-MFIS ES) is explicated in this phase. The fig. 1 shows the flow of proposed DHEPCPP-MFIS Expert System methodology. Proposed DHB-MFIS Expert System consist of layer as shown in fig. 2. In layer of proposed DHEPCPP-MFIS- ES diagnose the Health effects of pollution produced by coal power plants by using six input variables as shown in fig. 3 .

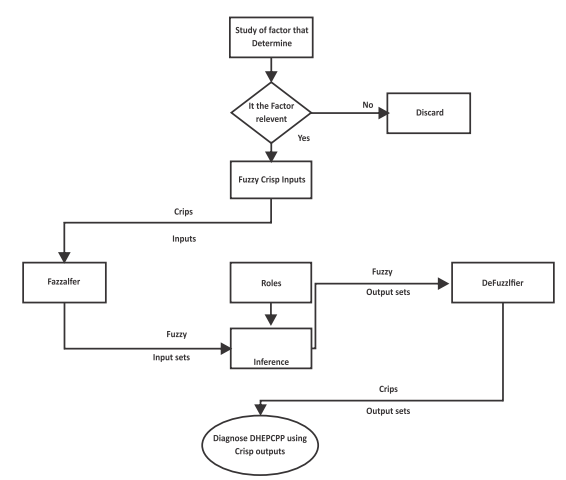

Fig. 1. Proposed DHEPCPP-MFIS Expert System 


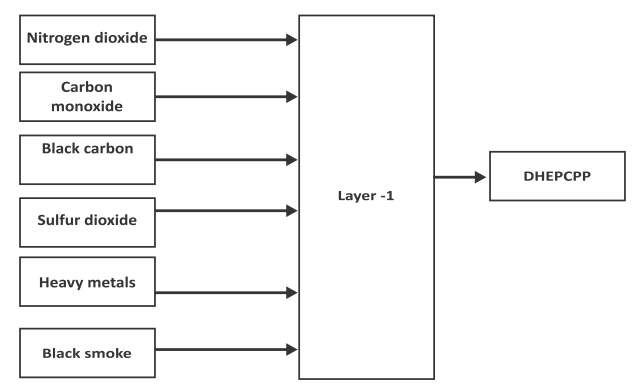

Fig. 2. Proposed DHEPCPP-MFIS Expert System

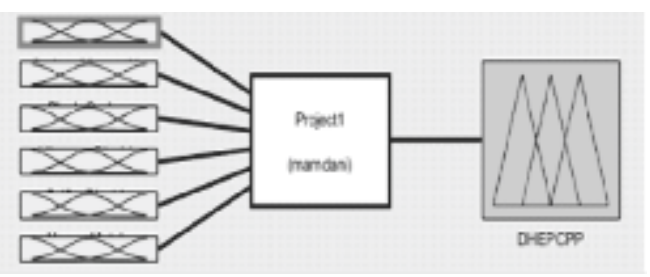

Fig. 3. Proposed DHEPCPP-MFIS ES

The values of Carbon monoxide (CO). Black carbon, Nitrogen dioxide (NO2), Sulfur dioxide (SO2), Heavy metals and Black smoke are used to make a fuzzy base Expert System. The Proposed DHEPCPP-MFIS Expert System mathematically can be written as

\section{${ }^{\mu \mathrm{D}} \mathrm{HEPCPP}=$ \\ MFIS}

$[\mu$ Carbon monoxide(CO), $\mu$ Black carbon, $\mu$ Nitrogen dioxide(NO2), $\mu$ Sulfuric dioxide (SO2), $\mu$ Heavy metals, $\mu$ Black smoke

\section{Input Fuzzy Sets}

Fuzzy input variables are numerical values that are used to diagnose the Health effects of pollution produced by coal power plants (DHEPCPP). In this paper, total six various types of input variables are used to diagnose the health effects of pollution produced by coal power plants. Table 1 shows the description of input variables.

\begin{tabular}{|l|l|l|}
\hline Sr \# & Output Variable & Semantic sign \\
\hline \multirow{3}{*}{1} & \multirow{2}{*}{ DHEPCPP } & Lung Problem \\
\cline { 3 - 3 } & & Heart Attack \\
\cline { 3 - 3 } & & Cancer \\
\hline
\end{tabular}

\section{Output Fuzzy Sets}

In this article, layer architecture is proposed to diagnose the Health effects of pollution produced by coal power plants. Fuzzy output variable is shown in table 2 .

Table 2. Layer input variable of Proposed DHEPCPP-MFIS Expert System.

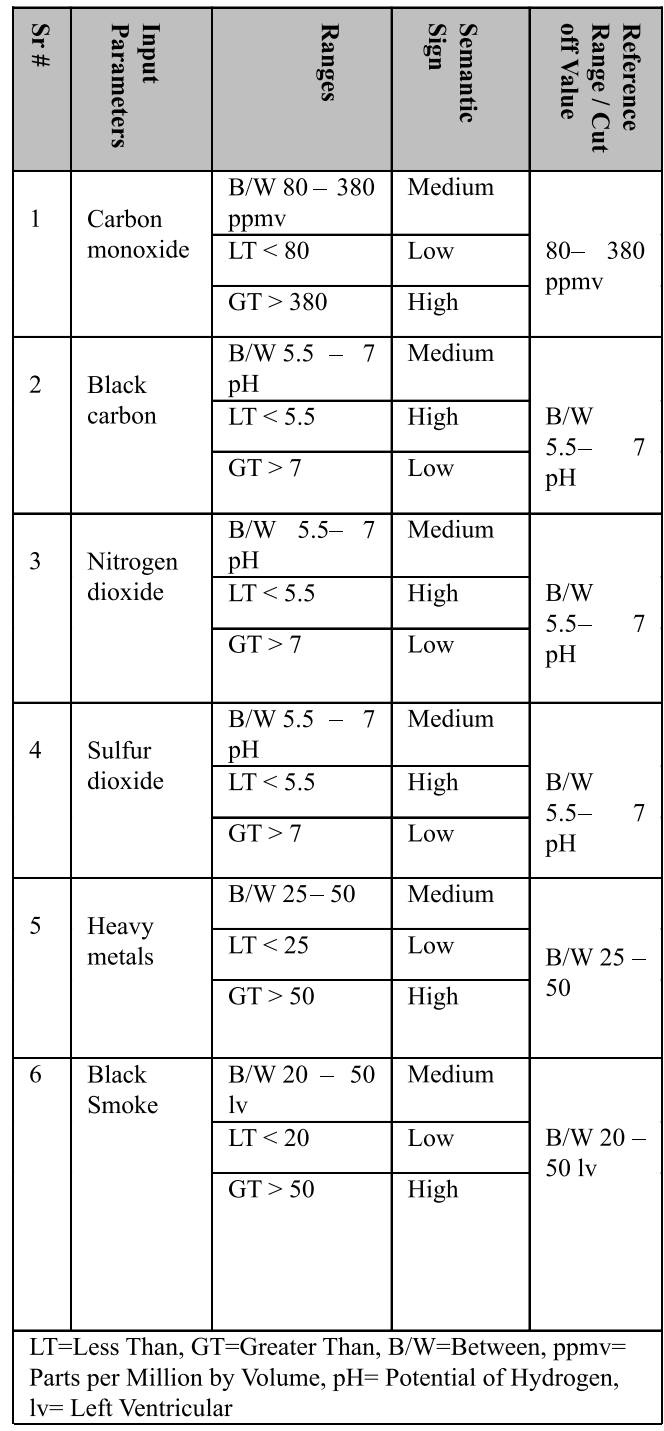

\section{Membership Functions}

In this article, three Standard membership functions are used. Which are given below

1. Trapezoidal Membership Function (Trapmf) 
Table 3. Standard membership function used in proposed DHEPCPP-MFIS Expert System

\begin{tabular}{|c|c|c|c|}
\hline $\begin{array}{l}\text { Sr. } \\
\text { No }\end{array}$ & $\begin{array}{l}\text { Function } \\
\text { Name }\end{array}$ & Function & Graphical Representation \\
\hline 1 & $\begin{array}{l}\text { Trapezoidal } \\
\text { Function } \\
\text { (Trapmf) }\end{array}$ & $\begin{array}{l}\boldsymbol{f ( x ,} \quad \boldsymbol{a}, \quad \begin{array}{c}\boldsymbol{b}, \quad \mathrm{c}, \quad \mathrm{d}) \\
0 .\end{array} \\
\left\{\begin{array}{cc}\left(\frac{x-a}{b-a}\right), & a \leq x \leq b \\
1, & b \leq x \leq c \\
\left(\frac{d-x}{d-c}\right), & c \leq x \leq d \\
0, & c \leq x\end{array}\right\}\end{array}$ & Here: $\boldsymbol{a}=0.1, \boldsymbol{b}$ \\
\hline 2 & $\begin{array}{l}\text { S-Shaped } \\
\text { Membership } \\
\text { Function (smf) }\end{array}$ & 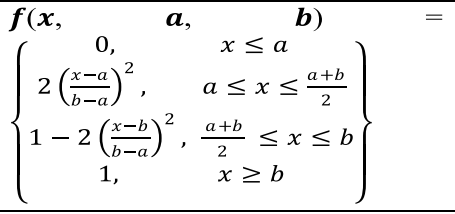 & Here: $\boldsymbol{a}=\mathbf{1}, \boldsymbol{b}=8$ \\
\hline 3 & $\begin{array}{l}\text { Z-Shaped } \\
\text { Membership } \\
\text { Function } \\
\text { (zmf) }\end{array}$ & $\begin{array}{l}\boldsymbol{f}\left(\boldsymbol{x}, \quad \boldsymbol{a}, \quad \begin{array}{c}\boldsymbol{b}) \\
1,\end{array}\right. \\
\left\{\begin{array}{cl}1-2\left(\frac{x-a}{b-a}\right)^{2}, & a \leq x \leq \frac{a+b}{2} \\
2\left(\frac{x-b}{b-a}\right)^{2}, & \frac{a+b}{2} \leq x \leq b \\
1, & x \geq b\end{array}\right\}\end{array}$ & Here: $\boldsymbol{a}=\mathbf{3}, \boldsymbol{b}=7$ \\
\hline
\end{tabular}

2. S-Shaped Membership Function (SMF)

3. Z-Shaped Membership Function (ZMF)

Graphical and mathematical representation of Proposed DHEPCPP-FS is shown in Table-3.

\section{Lookup Table}

The lookup table is developed after the gathering data from previous done researches on effect of coal pollution on health.

Table 4. Input and Output Variables Membership Functions used in Proposed ML-MFIS-DHB Expert System

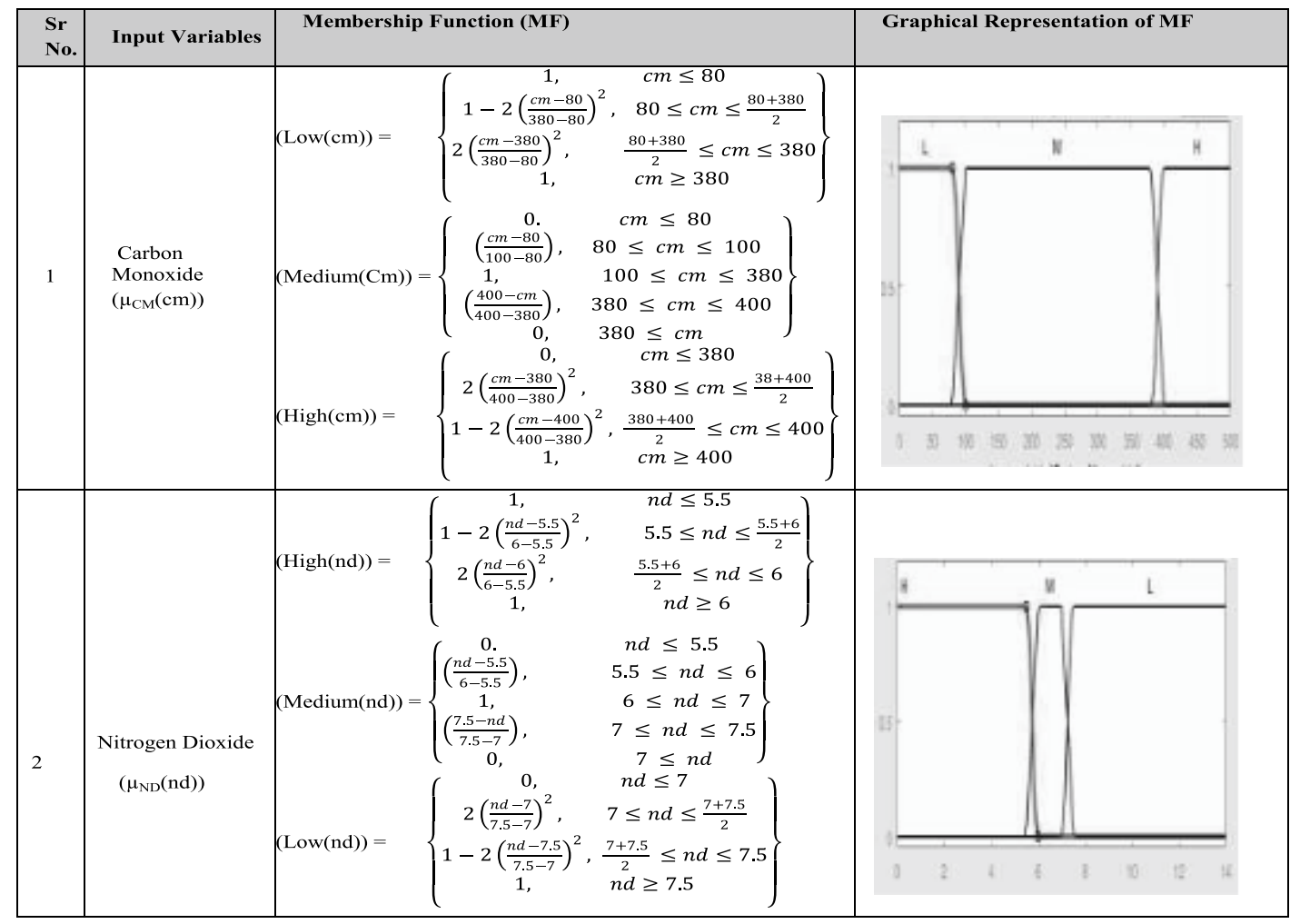

LGU Research Jounral for Computer Sciences \& IT 3(2) LGURJCSIT 


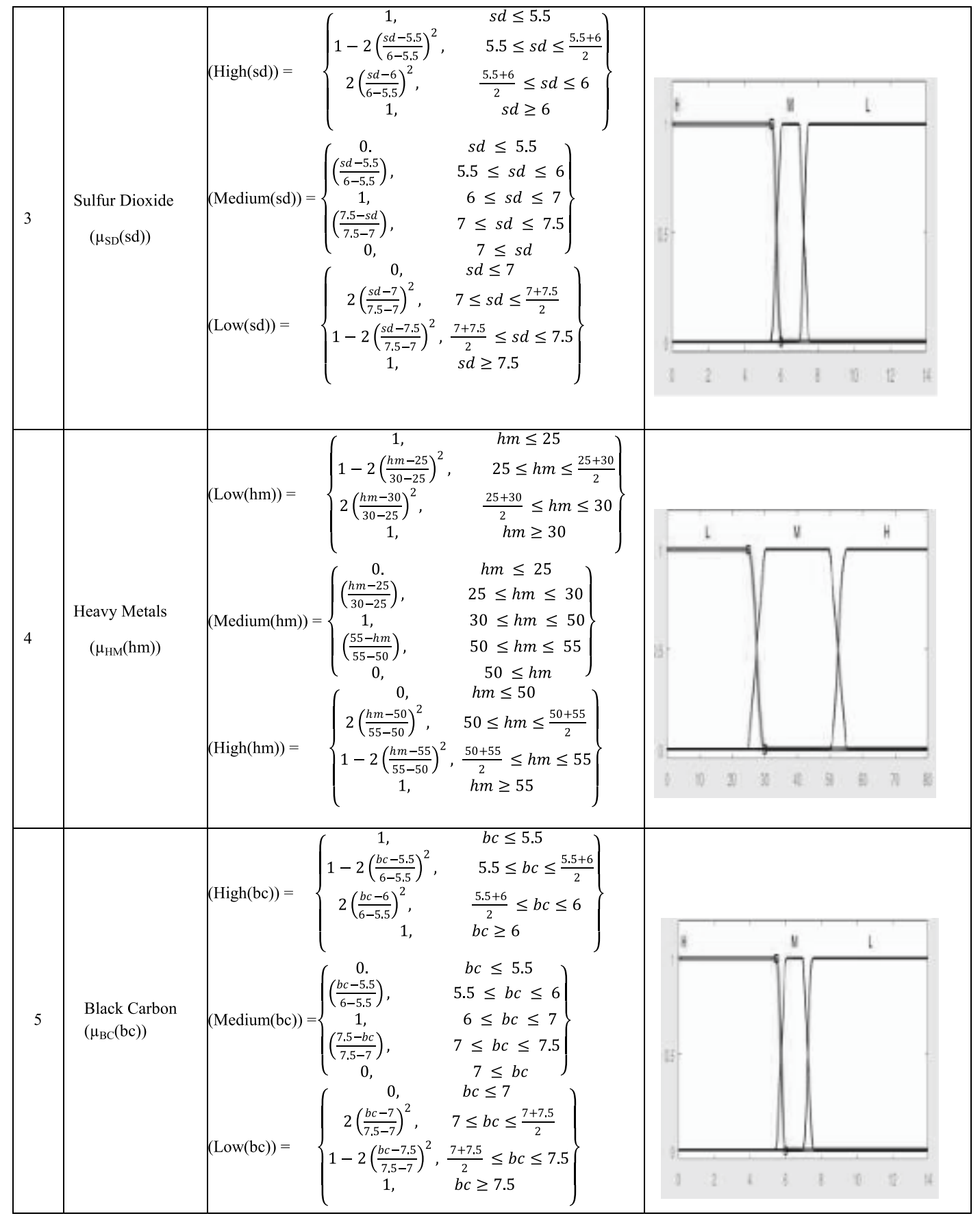




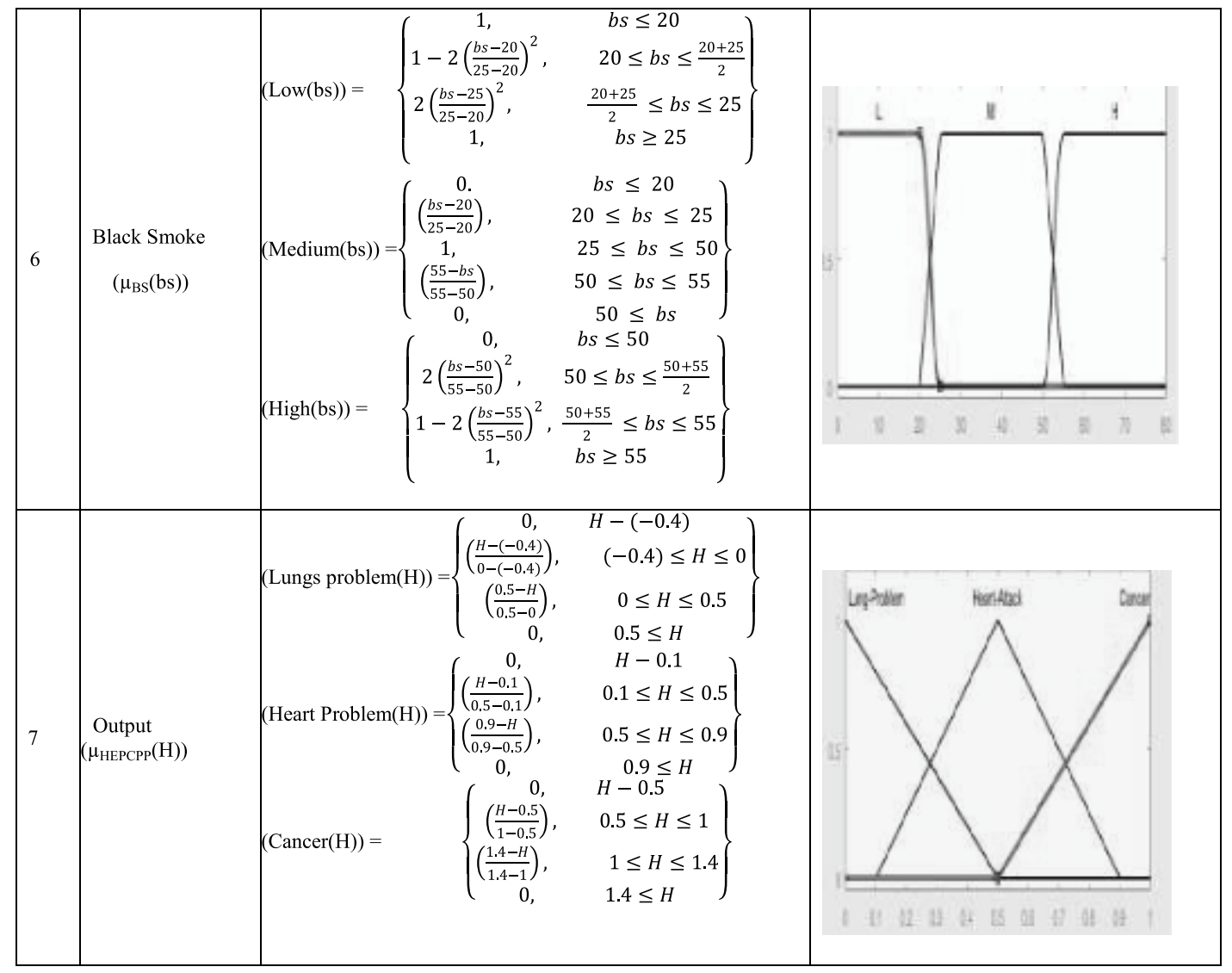

Table 5. Look up Table for Proposed DHEPCPP-MFIS Expert Syste

\begin{tabular}{|c|c|c|c|c|c|c|c|}
\hline 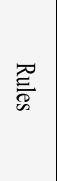 & 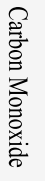 & 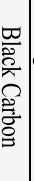 & 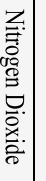 & 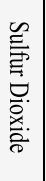 & 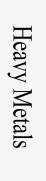 & 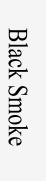 & 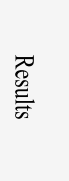 \\
\hline 1 & $\mathrm{~L}$ & $\mathrm{~L}$ & $\mathrm{~L}$ & $\mathrm{~L}$ & $\mathrm{~L}$ & $\mathrm{~L}$ & \multirow{6}{*}{ 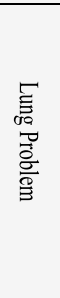 } \\
\hline 2 & L & $\mathrm{L}$ & $\mathrm{L}$ & $\mathrm{L}$ & L & $\mathrm{M}$ & \\
\hline 3 & $\mathrm{~L}$ & $\mathrm{M}$ & $\mathrm{H}$ & $\mathrm{L}$ & L & $\mathrm{L}$ & \\
\hline 4 & L & $\mathrm{M}$ & $\mathrm{H}$ & $\mathrm{L}$ & L & $\mathbf{M}$ & \\
\hline 5 & $\mathrm{M}$ & $\mathrm{M}$ & $\mathrm{L}$ & $\mathrm{M}$ & $\mathrm{M}$ & $\mathrm{H}$ & \\
\hline 6 & $\mathrm{M}$ & $\mathrm{M}$ & $\mathrm{L}$ & $\mathrm{M}$ & $\mathrm{H}$ & $\mathrm{L}$ & \\
\hline 7 & L & $\mathrm{L}$ & $\mathrm{H}$ & $\mathbf{M}$ & $\mathrm{H}$ & $\mathrm{M}$ & \multirow{4}{*}{ 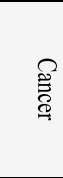 } \\
\hline 8 & $\mathrm{~L}$ & $\mathrm{~L}$ & $\mathrm{H}$ & $\mathbf{M}$ & $\mathrm{H}$ & $\mathrm{H}$ & \\
\hline 9 & $\mathrm{~L}$ & $\mathrm{H}$ & $\mathrm{L}$ & $\mathrm{M}$ & $\mathrm{L}$ & $\mathrm{M}$ & \\
\hline 10 & $\mathrm{~L}$ & $\mathrm{H}$ & $\mathrm{L}$ & $\mathbf{M}$ & $\mathrm{L}$ & $\mathrm{H}$ & \\
\hline 11 & $\mathrm{~L}$ & $\mathrm{~L}$ & $\mathrm{~L}$ & $\mathrm{H}$ & $\mathrm{M}$ & $\mathrm{L}$ & \multirow{5}{*}{ 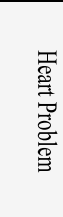 } \\
\hline 12 & $\mathrm{~L}$ & $\mathrm{~L}$ & $\mathrm{~L}$ & $\mathrm{H}$ & $\mathrm{M}$ & $\mathrm{M}$ & \\
\hline 13 & L & $\mathrm{M}$ & $\mathrm{H}$ & $\mathrm{H}$ & $\mathrm{L}$ & $\mathrm{L}$ & \\
\hline 14 & L & $\mathrm{M}$ & $\mathrm{H}$ & $\mathrm{H}$ & $\mathrm{L}$ & $\mathrm{M}$ & \\
\hline 15 & $\mathrm{~L}$ & $\mathrm{H}$ & $\mathrm{L}$ & $\mathrm{L}$ & $\mathrm{M}$ & $\mathrm{M}$ & \\
\hline
\end{tabular}

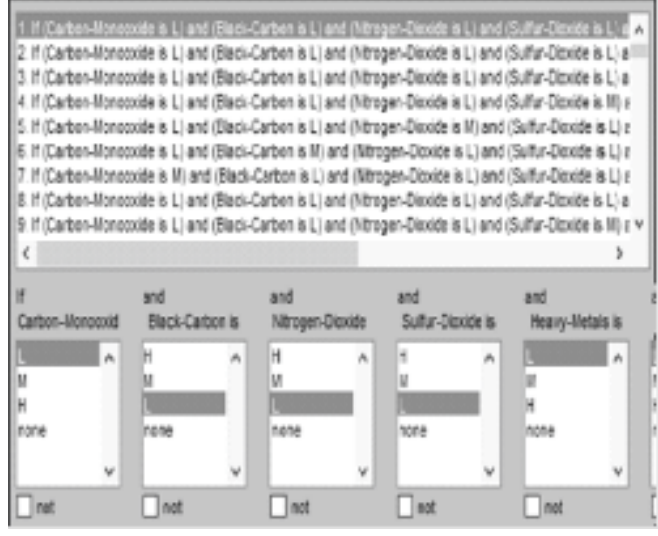

Fig. 4. Layer I/O rules for DHEPCPP MFIS Expert System

\section{Defuzzifier}

In fig. 8 MFIS Expert System shows the health effects of pollution produced by coal power plants in term of Probability based on six input parameters. It is observed that if (Carbon monoxide is less than 80ppmv) and (Black carbon is less than $5.5 \mathrm{pH}$ ) and (Nitrogen dioxide 
is less than $5.5 \mathrm{pH}$ ) and (Sulfur dioxide is less than $5.5 \mathrm{pH}$ ) and (Heavy metals is less than $25 \%$ ) and (Black smoke is less than 20lv) then it causes lungs problem. It also observed that if (Carbon monoxide lies b/w 80-380 ppmv) and (Black carbon lies between 5.5-7 pH) and (Nitrogen dioxide lies between 5.5- $7 \mathrm{pH}$ ) and (Sulfur dioxide is less than $5.5 \mathrm{pH}$ ) and (Heavy metals is more than 50\%) and (Black smoke is B/W 20 $50 \mathrm{lv}$ ) then it causes heart problem. It also shows that If (Carbon monoxide is more than $380 \mathrm{ppmv}$ ) and (Black carbon is less than $5.5 \mathrm{pH}$ ) and (Nitrogen dioxide is less than $5.5 \mathrm{pH}$ ) and (Sulfur dioxide is less than $5.5 \mathrm{pH}$ ) and (Heavy metals is less than 25\%) and (Black smoke is more the 50lv) then it causes cancer it means our System Diagnosis lungs problem, heart problem and cancer.

In addition, ultimate fig 5a-5d are representing Health effects of pollution caused by coal power plants. The Health effects of pollution produced by coal power plants results are the combination of at least six input variables.

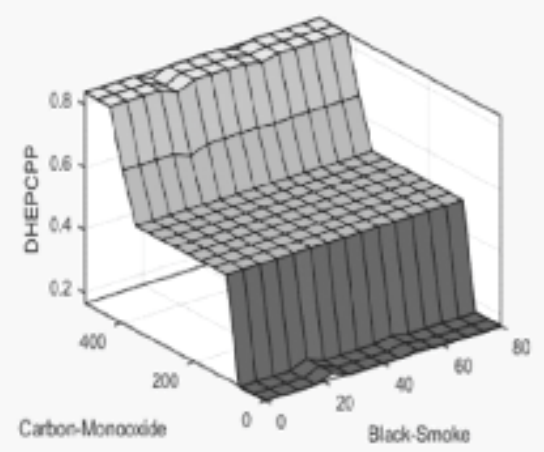

Fig.5a. Rule Surface for Carbon Monoxide and Black-Smoke

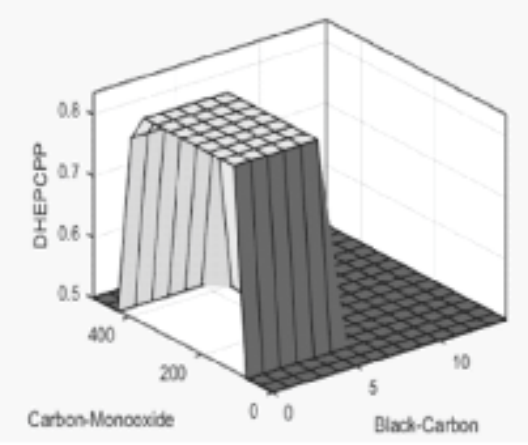

Fig. 5b. Rule Surface for Carbon-Monoxide and Black-Carbon

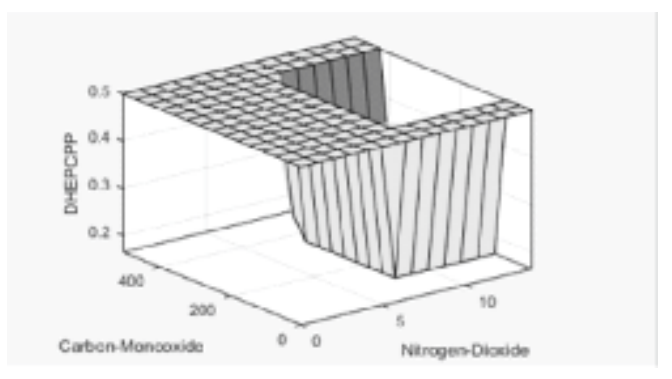

Fig. 5c. Rule Surface for Carbon-Monoxide and Nitrogen-Dioxide

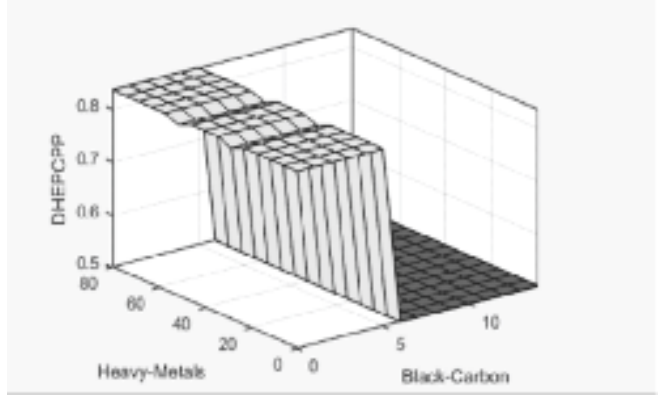

Fig. 5d. Rule Surface for Heavy-Metals and Black-Carbon

\section{Simulation Results}

MATLAB tool is used for simulation consequences. It is likewise used for modeling, simulation, algorithmic rule development, prototyping and plenty of different field. MATLAB has been efficiently used in computing, data analysis, programming and visualization. For imitation results, DHEPCPP used as output variable which correspond to six inputs variables. There are different types of Health effects of pollution caused by coal power plants like Lungs problem, Heart problem and Cancer etc. In this article, the suggested DHEPCPP-FS Smart System only diagnose different health effects of pollution caused by coal power plants like Lungs problem, Cancer etc.

Fig.6a shows that If(Carbon monoxide is less than 80ppmv) and (Black carbon is more than $7 \mathrm{pH}$ ) and (Nitrogen dioxide is more than $7 \mathrm{pH}$ ) and (Sulfur dioxide is more than $7 \mathrm{pH}$ ) and (Heavy metals is less than 25\%) and (Black smoke is less than 20lv) then it causes lungs problem. 


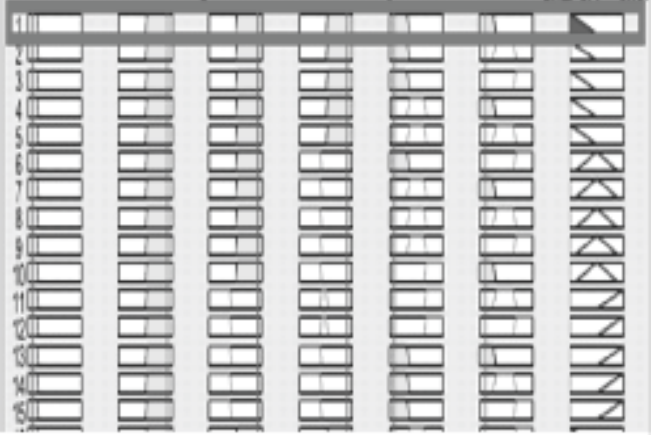

Fig.6a. Lookup diagram for Lungs problem

Fig.6b shows that if (Carbon monoxide less than 80ppmv) and (Black carbon is more than $7 \mathrm{pH}$ ) and (Nitrogen dioxide is more than $7 \mathrm{pH}$ ) and (Sulfur dioxide is less than $5.5 \mathrm{pH}$ ) and (Heavy metals lies between 20-50\%) and (Black smoke is less than $20 \mathrm{lv}$ ) then it causes heart attack.

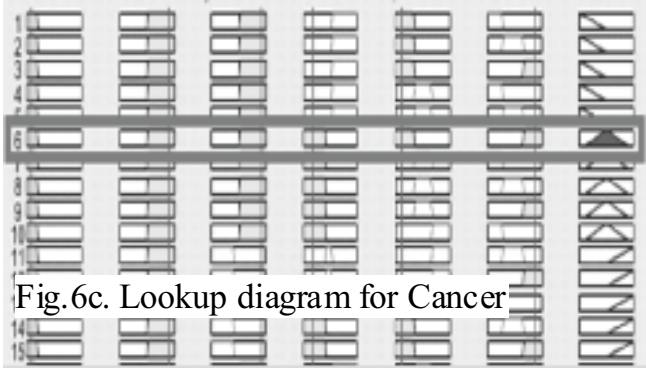

Fig.6b. Lookup diagram for Heart problem

Fig.6c shows that If (Carbon monoxide is less than $80 \mathrm{ppmv}$ ) and (Black carbon is more than $7 \mathrm{pH}$ ) and (Nitrogen dioxide is less than $5.5 \mathrm{pH}$ ) and (Sulfur dioxide lies between 5.5-7 pH) and (Heavy metals is more than 50\%) and (Black smoke lies between 20-50lv) then it causes cancer.

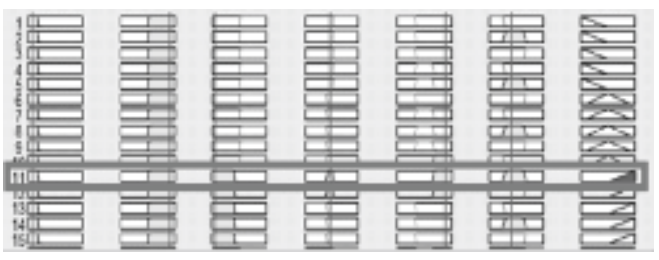

Fig.6c. Lookup diagram for Cancer

\section{Conclusion}

The main focus of this article is to design an expert system to diagnose Health effects of pollution, caused by coal power plants by $\mathrm{CBC}$ and ECG. The presented smart System is standard and easy to use for Medical specialists and non-medical professionals. A non-medical professional can also detect the health effects of pollution via their vital inputs. The overall accuracy of the Proposed DHEPCPP-FS smart System is $90.7 \%$. In future work, the performance of the proposed system can be progressed by the use of other parameters. The research work is more enhanced towards the other harmful effect of coal on health and make a system which prescribe the medicine for coaleffected patient.

\section{References}

[1] B. J. Berne, G. Cicootti, D. F. Coker, Classical and quantum dynamics in condensed phase simulations, (1998).

[2] J. I. Freijer, H. J. T. Bloemen, Modeling relationships between indoor and outdoor air quality. Journal of the Air \& Waste Management Association, 50(2), 292-300, (2000).

[3] E. Burt, P. Orris, S. Buchanan, Scientific evidence of health effects from coal use in energy generation. Chicago and Washington: School of Public Health, University of Illinois and Health Care Without Harm, (2013).

[4] N. Cheung, Machine learning techniques for medical analysis. School of Information Technology and Electrical Engineering (Doctoral dissertation, B. Sc. Thesis, University of Queen land), (2001).

[5] M. Neshat, Yaghobi. Mehdi, "Designing a fuzzy expert system of diagnosing the hepatitis $\mathrm{B}$ intensity rate and comparing it with adaptive neural network fuzzy system." Proceedings of the World Congress on Engineering and Computer Science. Vol. 2, (2009).

[6] D. C. Shin, Hazardous Air Pollutants: Case Studies from Asia. CRC Press, (2016).

[7] Anjali. Sardesai, "Fuzzy logic application in gynecology: A case study." Informatics, Electronics \& Vision (ICIEV), 2014 International Conference on. IEEE, 2014.

[8] Levy JI, Spengler JD. Modeling the benefits of power plant emission controls in Massachusetts. J Air Waste Manag Assoc. 2002;52(1):518. 
[9] G. Upadhyaya, N. Dashore, Monitoring of air polution by using fuzzy logic. International Journal on Computer Science and Engineering, 2(07), 2282-2286, (2010).

[10] A. Aggarwal, T. Choudhary, P. Kumar, A fuzzy interface system for determining Air Quality Index. In Infocom Technologies and Unmanned Systems (Trends and Future Directions)(ICTUS), 2017 International Conference on(pp. 786-790). IEEE, (2017).

[11] S. S. Lancaster, A fuzzy logic controller for the application of skin pressure. In Fuzzy Information, 2004. Processing NAFIPS'04. IEEE Annual Meeting of the (Vol. 2, pp. 686689). IEEE, (2004).

[12] A. Soni, S. Shukla, Application of neurofuzzy in prediction of air pollution in urban areas. IOSR J Eng, 2, 1182-1187, (2012).

[13] Manish. Rana, R. R. Sedamkar, "Design of Expert System for Medical Diagnosis Using Fuzzy Logic." International Journal of Scientific \& Engineering Research 4.6: 2914-2921, (2013).

[14] G. M. Kamath, B. Lokeshappa, Feasibility Analysis of Air Quality Indices using Fuzzy Logic. International Journal of Engineering Research And, V5 (08), (2016).

[15] P. Dagar, A. Jatain, D. Gaur, Medical diagnosis system using fuzzy logic toolbox. In Computing, Communication \& Automation (ICCCA), 2015 International Conference on (pp. 193-197). IEEE, (2015). 